individual districts, each currently with about 60 deaths from breast cancer a year, would scarcely be measurable in the short to medium term, even if an efficient deployment were immediately attained. It would therefore seem sensible to conduct sequential and comparative evaluations for groups of 10 or 20 health districts rather than for one or two.

The working group calculated a cost of $£ 3000$ to $£ 3400$ for one life year saved, at 1985-6 prices. The exact workings are not easy to follow, but a parallel estimate is possible. The report estimates annual running costs of about $£ 18$ million plus amortisation on a capital investment of $£ 31$ million-say $£ 25$ million overall. The model estimate of 901 deaths and 21065 life years saved in England and Wales therefore suggests a non-discounted cost of $\$ 27747$ for each death saved and $\$ 1176$ for each life year saved. Discounting at $5 \%$ a year (as used by Forrest) between the year of the investment and the year of the benefit brings the cost of each life year saved to $£ 2591$, rather better than the Forrest estimates. ${ }^{1}$ The report does not give an estimate of costs for each death from breast cancer saved, but discounting our own estimate at the same rate over seven years gives a corresponding value of $£ 39043$.

This work was carried out as part of a health services research programme supported by the Department of Health and Social Security.

\section{Forrest P. Breast cancer screening. London: HMSO, 1986. \\ Shapiro S, Strax P, Venet L. Periodic breast cancer screening in reducing mortality from breast cancer. $7 A M A$ 1971;215:1777-85. \\ 3 Shapiro $\mathrm{S}$. Evidence on screening for breast cancer from a randomised trial. Cancer 1977;39:2772-82. \\ 4 Shapiro S, Venet W, Strax P, Venet L, Roeser R. Ten- to fourteen-year effect of breast cancer screening on mortality. Fournal of the National Cancer Institute 1982;69:349-59. \\ 5 Tabar L, Gad A, Holmberg LH, et al. Reduction in mortality from breast cancer after mass screening with mammography. Randomised trial from the Breas Cancer Screening Working Group of the Swedish National Board of Health and Welfare. Lancet 1985;i:829-32. \\ 6 Knox EG. Computer simulations of cervical cytology screening programmes. In:McLachlan G, ed. Future- and present indicatives. Problems and progress in medical care. London: Oxford University Press (for the Nuffield Provincial Hospitals Trust), 1973:30-55. \\ Knox EG Simulation studies of breast cancer screening programmes. In McLachlan G, ed. Probes for health. London: Oxford University Press (for the Nuffield Provincial Hospitals Trust), 1975: 14-44. \\ $8 \mathrm{Knox}$ EG. Ages and frequencies for cervical cancer screening. $\mathrm{Br} \mathrm{J}$ Cancer 1976;3:444-52 \\ (Accepted 23 May 1988}

\title{
Outcome of untreated infection with Entamoeba histolytica in homosexual men with and without HIV antibody
}

\author{
Erica Allason-Jones, Adrian Mindel, Peter Sargeaunt, David Katz
}

Academic Department of Genito-Urinary Medicine and Bland-Sutton Institute of Pathology, University College and Middlesex School of Medicine, London WIN 8AA Erica Allason-Jones, MRCP, lecturer

Adrian Mindel, MRCP, senior lecturer

David Katz, MRCP, reader in experimental pathology

Department of Medical Protozoology, London School of Hygiene and Tropical Medicine, London WC1E 7HT

Peter Sargeaunt, senior chief medical laboratory scientific officer

Correspondence and requests for reprints to: $\mathrm{Dr}$ Allason-Jones.

\begin{abstract}
Among homosexual men the prevalence of infection with Entamoeba histolytica is high. To determine the clinical importance of this infection 55 homosexual men carrying the parasite were investigated in detail. No clinical, serological, or histological evidence of invasive amoebiasis was found in any of them. The patients were not treated and were followed up for 12 to 29 months (mean 21.6 months), during which period none developed symptoms that could be attributed to $E$ histolytica. Spontaneous loss of the parasite occurred in 17 patients, some of whom later became reinfected. Sixteen patients had antibody to human immunodeficiency virus, and infection with $E$ histolytica showed the same benign course in them as in the patients who did not have antibody. Throughout the study classification of the isolates of $E$ histolytica consistently showed that they belonged only to non-pathogenic zymodemes. The findings provide further evidence that $E$ histolytica in homosexual men is a commensal organism.
\end{abstract}

\section{Introduction}

Sexual transmission of Entamoeba histolytica has led to a high prevalence of infection among homosexual men. ${ }^{1-12}$ Several studies have been unable to find any correlation between gastrointestinal symptoms and the presence or absence of $E$ histolytica, ${ }^{136791113}$ and clinical investigations in a few infected men have shown no evidence of invasive disease..$^{1214}$ is Reports that describe invasive amoebiasis in homosexual men are extremely rare. ${ }^{16-19}$

The introduction of zymodeme classification (the grouping of isolates according to their isoenzyme pattern on electrophoresis) has provided a rational explanation for the lack of clinical disease in many people infected with $E$ histolytica. Twenty two different zymodemes of $E$ histolytica have been shown, 12 of which have never been associated with invasive amoebiasis and have therefore been designated non- pathogenic. ${ }^{20-29}$ Classification of isolates of $E$ histolytica from homosexual men in the United Kingdom and North America has to date shown them all to belong to non-pathogenic zymodemes. ${ }^{511141530}$ Information on the natural course of infections with non-pathogenic $E$ histolytica is scant. In a study that followed up 15 subjects passing cysts of $E$ histolytica, some of which were known to be non-pathogenic, all subjects lost the parasite within 18 months. ${ }^{31}$ No such study has been carried out on homosexual men, a group in which the high prevalence of infection with human immunodeficiency virus (HIV) and consequent immune suppression are added complications. We therefore investigated a cohort of 55 homosexual men known to be infected with $E$ histolytica for evidence of invasive amoebiasis and followed them up without treatment to establish the natural course of the infection.

\section{Patients and methods}

We identified patients by random screening, ${ }^{11}$ screening during the investigation of gastrointestinal symptoms, and screening sexual partners of men known to be infected with $E$ histolytica. We took a full history from each patient and gave them a general examination. A proctoscope was passed, and specimens were taken for culture for Neisseria gonorrhoeae, Chlamydia trachomatis, and herpes simplex virus. A blood sample was taken to test for antibodies to amoebas and HIV. Faecal specimens were examined for parasites, including cryptosporidium, and were cultured for salmonellas, shigellas, campylobacter, and yersinia. After these additional infections had been treated or excluded patients who had no contraindication and agreed to the procedure underwent sigmoidoscopic examination, during which two rectal biopsy specimens were taken, one for histological examination and the other for culture of amoebas.

To determine the natural course of infection with $E$ histolytica we did not treat the patients but reassessed 
them at three month intervals. At each visit we recorded details of any gastrointestinal symptoms and coincidental treatment and carried out a general examination; at least one fresh stool sample was examined for the presence of parasites. The patients were considered to be clear of $E$ histolytica if three consecutive stool specimens gave negative results. They were encouraged to reattend immediately if any gastrointestinal symptoms developed.

Laboratory investigations-Stool samples were examined for parasites by both microscopy and culturing. For microscopy the specimens were concentrated by the formol-ether technique ${ }^{32}$ and stained with double strength Lugol's iodine and Sargeaunt's stain..$^{33}$ All specimens were cultured in Robinson's medium regardless of the results of microscopy, ${ }^{34}$ and cultures of $E$ histolytica classified into zymodemes. ${ }^{28}$ Phenol auramine fluorescence microscopy was used to identify cryptosporidium, ${ }^{35}$ and routine techniques were used to isolate faecal bacteria and rectal pathogens. Rectal biopsy specimens for histological examination were mounted on glass microfibre and fixed immediately in acid formalin. The tissue was processed overnight at $4^{\circ} \mathrm{C}$ on a Lynx tissue processor, orientated at $90^{\circ} \mathrm{C}$ to the muscularis, and embedded in paraffin. Serial sections were stained routinely with haematoxylin and eosin. The second rectal biopsy in each case was placed in Robinson's medium to culture amoebas and the zymodeme characterised for those cultures obtained.

Antibodies to $E$ histolytica were detected on indirect immunofluorescence antibody testing and antibodies to HIV by competitive enzyme linked immunosorbent assay (ELISA) (Wellcozyme)

Statistical analysis - The duration of infection with $E$ histolytica in the patients with and without antibody to HIV was compared by a log rank test. The characteristics of patients still infected and those who lost the parasite were compared by Fisher's exact test.

\section{Results}

\section{INITIAL INVESTIGATIONS}

Fifty five patients were studied, of whom 44 were identified during random screening, six were being investigated for gastrointestinal complaints, and five were sexual partners of men already recruited. Clinical

Organisms and conditions identified in 55 homosexual men excreting $E$ histolytica

\begin{tabular}{lc}
\hline & $\begin{array}{c}\text { No of } \\
\text { men }\end{array}$ \\
\hline Neisseria gonorrhoeae & 1 \\
Herpes simplex virus & 3 \\
Enterobius vermicularis & 1 \\
Giardia lamblia & 3 \\
Other amoebic species & 37 \\
Yersinia fredericksenii & 1 \\
Spirochaetosis & 5 \\
Anal warts & 7
\end{tabular}

*Including Entamoeba coli, Entamoeba hartmanni, Endolimax nana, Iodamoeba bütschlii, and Dientamoeba fragilis.

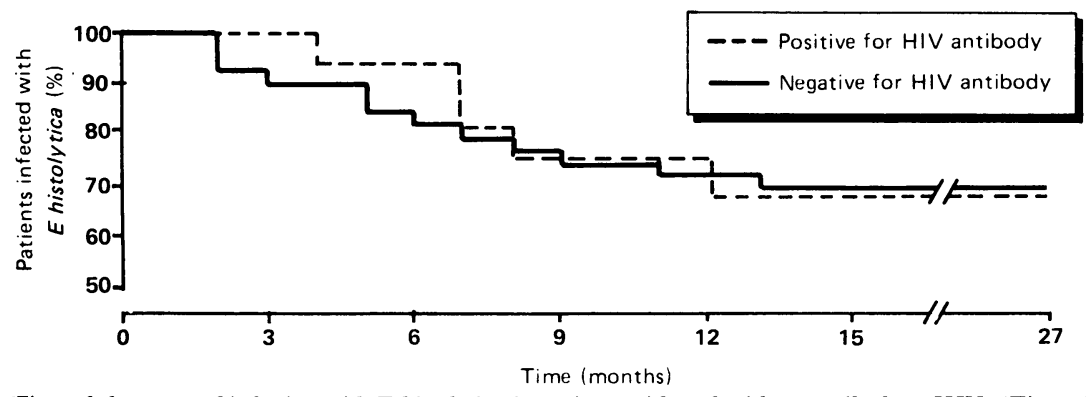

Time of clearance of infection with $E$ histolytica in patients with and without antibody to HIV. (Time of clearance of parasite taken as time at which first sample of three consecutive stool samples giving negative results was received.) features of amoebic infection were not found. One patient had generalised lymphadenopathy and one had seborrhoeic dermatitis; both were positive for antibody to HIV. One patient had a colostomy after previous excision of a rectal carcinoma.

Proctoscopy was carried out in 54 men and sigmoidoscopic examination in 47 . Of the eight who did not undergo sigmoidoscopy, three had declined it, one was the patient with a colostomy, and four had relative contraindications such as anticoagulant treatment or valvular heart disease. Mild mucosal erythema was noted on endoscopy in 10 patients, but no features of invasive amoebiasis were seen in any case. Histological examination showed minimal non-specific inflammatory changes in six biopsy specimens, but features of invasive amoebiasis were not seen.

$E$ histolytica was cultured from 18 of the 47 biopsy specimens. Characterisation of the zymodeme of all isolates cultured from faecal and rectal biopsy specimens showed that they belonged to I, III, or VIII which are non-pathogenic. In seven patients cultures of $E$ histolytica were not isolated from either faeces or rectal biopsy specimens at this stage, and consequently the zymodeme could not be identified. The table shows the other organisms and conditions identified in the 55 patients.

Antibodies to $E$ histolytica were not detected in any of the patients. Thirteen patients were found to be positive for antibody to HIV on enrolment into the study, and three developed antibodies during follow up.

\section{FOLLOW UP}

Patients were followed up for 12-29 months (mean 21.6 months), during which a total of 363 faecal specimens were examined (4-12 per patient) and 172 isolates of $E$ histolytica were successfully cultured, all of which belonged to non-pathogenic zymodemes. In two patients the zymodeme was not identified because culturing was unsuccessful. None of the patients developed disease that was related to $E$ histolytica. Although many episodes of brief self limiting gastrointestinal disturbances were reported, only six patients developed symptoms that warranted investigation. The diagnoses in these six cases were acute appendix abscess (one), diverticulitis (one), infection with Giardia lamblia (one) or Shigella flexneri (one), and self limiting diarrhoea with no recognised cause (two). Six cases of asymptomatic giardiasis were identified during follow up.

Seventeen patients spontaneously became clear of $E$ histolytica during follow up, as judged by negative results on examination of a minimum of three consecutive stool samples. Five of these patients were positive for antibody to HIV and 12 negative; the time to clearance of the parasite was not significantly different between patients who did and did not have antibody to HIV (figure). Subsequently seven patients became reinfected, again with non-pathogenic zymodemes of $E$ histolytica. Thirty eight patients remained infected throughout the study, including 11 of the patients with antibody to HIV.

A significant association was noted between loss of the parasite and diarrhoea; of the 17 subjects who became clear of infection, four had experienced an episode of diarrhoea sufficiently severe to seek medical advice and in all four this coincided with the change from being positive for $E$ histolytica to being negative on examination of stools, whereas none of the 38 patients still infected complained of diarrhoea $(p=0.007)$. During follow up 13 patients were prescribed metronidazole, tetracycline, or erythromycin for coincidental problems such as gingivitis, gonorrhoea, and non-specific urethritis. These three drugs are used for treating amoebiasis, yet in only two 
cases did treatment (with tetracycline) coincide with loss of the parasite. This apparent lack of efficacy in clearing $E$ histolytica may have been due to the use of dosage regimens below those used to treat amoebiasis.

Three patients developed AIDS. In one $E$ histolytica was cultured from a histologically normal rectal biopsy specimen taken only six weeks before he presented with pneumonia caused by Pneumocystis carinii. He had no gastrointestinal symptoms until his admission with pneumonia, when diarrhoea also developed. Several stool samples were subsequently examined and cryptosporidium was identified, but he was no longer infected with $E$ histolytica. Another patient developed lobar pneumonia secondary to septicaemia caused by Salmonella choleraesuis and a few months later presented with pneumonia due to $P$ carinii; he remained infected with $E$ histolytica and never had any gastrointestinal symptoms. The third patient, who was still infected with $E$ histolytica, developed Kaposi's sarcoma. One patient with antibody to HIV, still infected with $E$ histolytica but without gastrointestinal symptoms, developed oral candidiasis and hairy leucoplakia.

\section{Discussion}

Only two studies have looked in detail for evidence of invasive amoebiasis in homosexual men infected with $E$ histolytica. McMillan et al favoured treating such patients because they found endoscopic and histological abnormalities more commonly in infected patients than uninfected controls, ${ }^{14}$ but the abnormalities were those of non-specific proctitis, a common problem in homosexual men that cannot be equated with amoebic colitis. Goldmeier et al questioned the need to treat homosexual men infected with $E$ histolytica but ultimately made no firm recommendation. ${ }^{15}$ On the basis of our study we suggest that homosexual men passing cysts of $E$ histolytica in the faeces can safely be left untreated.

The spread of AIDS among the homosexual population, in which non-pathogenic $E$ histolytica is already endemic, has raised concern about the clinical effect of combined infection. ${ }^{736}{ }^{37}$ The suggestion that the ability of $E$ histolytica to cause disease is altered in patients who are immunosuppressed has usually been supported by reference to a few reports of invasive amoebiasis in patients receiving steroid treatment. ${ }^{38.43}$ These cases occurred before the introduction of zymodeme classification, there is no contemporary evidence to suggest that non-pathogenic zymodemes can cause disease even in immunocompromised subjects. The patients in our cohort with antibodies to HIV showed no evidence of invasive amoebiasis, and the infection in them followed the same benign course as that in subjects who did not have antibody to HIV. The patients who developed AIDS either lost the parasite spontaneously or remained asymptomatic.

Most of our patients remained infected with $E$ histolytica; this contrasts with the findings of Nanda et $a l,{ }^{31}$ who reported that all 15 of their subjects spontaneously lost the parasite within 18 months. ${ }^{31} \mathrm{~A}$ possible explanation for this difference is that our criterion for accepting loss of the parasite (negative results in three consecutive stool samples) was stricter than theirs (one negative specimen) or that we underestimated the frequency of reinfection. Reinfection was documented in seven of the 17 subjects who fulfilled the criterion for loss of the parasite, but others may have lost and reacquired infection between assessments.

By our criterion one third of our patients became free of the infection. Why this should occur is not clear; it seems not to be related to coincidental antibiotic treatment. The association between loss of the parasite and diarrhoea suggests that an episode of rapid intestinal transit may clear the organism. Nanda et al reported that among patients with the irritable bowel syndrome the prevalence of $E$ histolytica was lower in the group who had diarrhoea than in the group who did not. ${ }^{31}$ Flushing the bowel in this way may be sufficient to dislodge an organism that has not invaded host tissue. This hypothesis, however, leaves 13 of our patients who either did not report episodes of diarrhoea or became free of infection for some other reason.

In summary, this study confirms that the $E$ histolytica circulating in the homosexual community in the United Kingdom is a commensal organism. Many patients will lose the parasite spontaneously, and others remain infected but asymptomatic. Even in patients infected with HIV the organism does not seem to be clinically important. We do not recommend routine treatment of homosexual men found to be passing cysts of $E$ histolytica, and if such patients present with gastrointestinal complaints $E$ histolytica should not be considered to be the cause unless there is evidence of invasive amoebiasis.

The study was supported by the Medical Research Council. We thank Mrs Sandra Wiffen for her help with analysing zymodemes, Mr Peter Williams for help with the statistical analysis, Ms Suzanne Fleck and Ms Jennifer Tosswill for testing for antibody to amoebas and the department of virology at University College and Middlesex Hospital School of Medicine for testing for HIV antibody.

1 William DC, Shookhoff HB, Felman YM, De Ramos SW. High rates of enteric protozoal infections in selected homosexual men attending a venereal disease clinic. Sex Transm Dis 1978;5:155-7.

$2 \mathrm{Kean} \mathrm{BH}$, William DC, Luminais SK. Epidemic of amoebiasis and giardiasis in a biased population. British fournal of Venereal Diseases 1979;55:375-8.

3 Keystone JS, Keystone DL, Proctor EM. Intestinal parasitic infections in homosexual men: prevalence, symptoms and factors in transmission. Can Med Assoc f 1980;123:512-4

4 Phillips SC, Mildvan D, William DC, Gelb AM, White MC. Sexual transmission of enteric protozoa and helminths in a venereal-disease-clinic population. N Engl f Med 1981;305:603-6.

5 Sargeaunt PG, Oates JK, Maclennan I, Oriel JD, Goldmeier D. Entamoeba histolytica in male homosexuals. British fournal of Venereal Diseases 1983;59: $193-5$.

6 Bienzle U, Coester $\mathrm{CH}$, Knobloch J, Guggenmoos-Holzmann I. Protozoal enteric infections in homosexual men. Klin Wochenschr 1984;62:323-7.

Chin ATL, Gerken A. Carriage of intestinal protozoal cysts in homosexuals. British fournal of Venereal Diseases 1984;60:193-5.

8 Hakansson C, Thoren K, Norkrans G, Johannisson G. Intestinal parasitic infection and other sexually transmitted diseases in asymptomatic homoinfection and other sexually transmitted diseases
sexual men. Scand f Infect Dis 1984;16:199-202.

9 Markell EK, Havens RF, Kurtsubo RA, Wingerd J. Intestinal protozoa in homosexual men of the San Francisco Bay area: prevalence and correlates of homosexual men of the San Francisco Bay area: pr.
infection. Am f Trop Med Hyg 1984;33:(2)239-45.

10 Jokipii L, Pohjola S, Valle S-L, Jokipii AMM. Frequency, multiplicity and repertoire of intestinal protozoa in healthy homosexual men and in patients with gastrointestinal symptoms. Ann Clin Res 1985;17:57-9.

11 Allason-Jones E, Mindel A, Sargeaunt P, Williams P. Entamoeba histolytica as a commensal intestinal parasite in homosexual men. N Engl f Med 1986;315: $353-6$

12 Sorvillo FJ, Strassburg MA, Seidel J, et al. Amebic infections in asymptomatic homosexual men, lack of evidence of invasive disease. Am $\mathcal{f}$ Pub Heallh 1986;76:1137-9.

13 Quinn TC, Stamm WE, Goodell SE, et al. The polymicrobial origin of intestinal infections in homosexual men. N Engl f Med 1983;309:576-82.

14 McMillan A, Gilmour HM, McNeillage G, Scott GR. Amoebiasis in homosexual men. Gut 1984;25:356-60.

15 Goldmeier D, Sargeaunt PG, Price AB. Is Entamoeba histolytica in homosexual men a pathogen? Lancet 1986;i:641-4.

16 Burnham WR, Reeve RS, Finch RG. Entamoeba histolytica infection in male homosexuals. Gut 1980;21:1097-9.

17 Ylvisaker JT, McDonald GB. Sexually acquired amebic colitis and liver abscess. West $\mathcal{F}$ Med 1980;132:153-7.

18 Thompson JE, Freischlag J, Thomas DS, Amebic liver abscess in a homosexual man. Sex Transm Dis 1983;10:153-5.

9 Saltzberg DM, Hall-Craggs M. Fulminant amebic colitis in a homosexual man. Am f Gastroenterol 1986;81:209-12.

20 Sargeaunt PG, Williams JE. Electrophoretic isoenzyme patterns of Entamoeba histolytica and Entamoeba coli. Trans R Soc Trop Med Hyg 1978;72:164-6.

21 Sargeaunt PG, Williams JE, Grene JD. The differentiation of invasive and non-invasive Entamoeba histolytica by isoenzyme electrophoresis. Trans $R$ Soc Trop Med Hyg 1978;72:519-21.

22 Sargeaunt PG, Williams JE, Kumate J, Jimenez E. The epidemiology of Entamoeba histolytica in Mexico City: a pilot survey I. Trans $R$ Soc Trop Med Hyg 1980;74:653-6.

23 Jackson TFHG, Sargeaunt PG, Williams JE, Simjee AE. Observations on zymodeme studies of Entamoeba histolytica in Durban, South Africa. Arch Invest Med (Mex) 1982;13(suppl 3):83-8.

24 Sargeaunt PG, Jackson TFHG, Simjee A. Biochemical homogeneity of Entamoeba histolytica isolates, especially those from liver abscess. Lancet 1982;i:1386-8

25 Sargeaunt PG, Williams JE, Bhoinani R, Campos JE, Gomez A. The epidemiology of Entamoeba histolytica in a rural and an urban area of Mexico: a pilot survey II. Trans $R$ Soc Trop Med Hyg 1982;76:208-10. 
26 Sargeaunt $P G$, Williams JE, Bhoinani $R$, Kumate J, Jimenez E. A review of isoenzyme characterization of Entamoeba histolytica with particular reference to pathogenic and non-pathogenic stocks isolated in Mexico. Arch Invest Med (Mex) 1982:13(suppl 3):89-94.

27 Sargeaunt PG, Williams JE, Jackson TFHG, Simjee AE. A zymodeme study of Entamoeba histolytica in a group of South African school children. Trans $R$ Soc Trop Med Hyg 1982;76:401-2.

28 Sargeaunt PG, Baveja UK, Nanda R, Anand BS. Influence of geographical factors in the distribution of pathogenic zymodemes of Entamoeba histolytica: identification of zymodeme XIV in India. Trans $R$ Soc Trop Med Hyg 1984;78:96-101.

29 Gathiram V, Jackson TFHG. Frequency distribution of Entamoeba histolytica zymodemes in a rural South African population. Lancet 1985; ; $719-21$.

30 Mathews HM, Moss DM, Healy GR, Mildvan D. Isoenzyme analysis of Entamoeba histolytica isolated from homosexual men. I Infect Dis 1986;153: Entar

31 Nanda R, Baveja U, Anand BS. Entamoeba histolytica cyst passers: clinical features and outcome in untreated subjects. Lancet 1984;ii:301-3.

2 Ridley DS, Hawgood BC. The value of formol-ether concentration of faecal cysts and ova. I Clin Pathol 1956;9:74-6.

3 Sargeaunt PG. Confirmation of amoebic cyst chromatoids by wet stain after Ridley's faecal concentration. Trans $R$ Soc Trop Med Hyg 1962;56:12.
34 Robinson GL. The laboratory diagnosis of human parasitic amoebae. Trans $R$ Soc Trop Med Hyg 1968;62:285-94.

5 Nichols G, Thom BT. Screening for cryptosporidium in stools. Lancel 1984;i:735.

36 Petri WA, Ravdin JL. Treatment of homosexual men infected with Entamoeba histolytica. $N$ Engl f Med 1986;315:393.

$37 \mathrm{Krogstad}$ DJ. Isoenzyme patterns and pathogenicity in amebic infection. NEnglf Med 1986;315:390-1.

38 Eisert J, Hannibal JE, Sanders SL. Fatal amebiasis complicating corticosteroid management of pemphigus vulgaris. $N$ Engl J Med 1959;261 843-5.

39 Mody VR. Corticosteroids in latent amoebiasis. Br Med J 1959;ii: 1399.

40 McAllister TA. Diagnosis of amoebic colitis on routine biopsies from rectum and sigmoid colon. Br Med $\mathcal{f} 1962 ; \mathrm{i}: 362-4$

41 Kanani SR, Knight R. Relapsing amoebic colitis of 12 years standing exacerbated by corticosteroids. BrMed I 1969;ii:613-4.

$42 \mathrm{Kanani}$ SR, Knight R. Amoebic dysentery precipitated by corticosteroids. $\mathrm{Br}$

43 Stuiver PC, Goud TJLM. Corticosteroids and liver amoebiasis. Br Med $\mathcal{J}$ 1978;ii:394-5.

(Accepted 25 May 1988)
CRC Cancer Epidemiology Unit, University of Edinburgh, Edinburgh EH8 9JZ

L J Kinlen, FRCP, director

Social and Environmental Epidemiology Branch, National Heart, Lung and Blood Institute, National Institutes of Health,

Bethesda, Maryland, USA

E Rogot, MA, statistician

Correspondence to: Dr Kinlen.

\title{
Leukaemia and smoking habits among United States veterans
}

\author{
L J Kinlen, E Rogot
}

\section{Abstract}

The relation between leukaemia and smoking habits was examined in data from the veterans' smoking study, a prospective study of mortality among 248000 United States veterans, of whom 723 died of leukaemia during 1954-69. A significant increase in mortality from leukaemia among cigarette smokers (relative risk 1.53) was found, together with a dose-response relation with amount smoked (trend $\mathbf{p}<\mathbf{0 . 0 0 1}$ ). The relation was strongest (relative risk 1.72) for monocytic and chronic and unspecified myeloid leukaemias (ICD (7th revision) codes 204.1 and 204.2). For these leukaemias the increase was almost twofold (relative risk 1.93) among current smokers of over 20 cigarettes daily. Ex-cigarette smokers also showed an increase of leukaemia (relative risk $1.39 ; \mathbf{p}<0.001$ ).

These findings are consistent with other studies and relevant to the interpretation of minor increases of leukaemia both in population and in individual based studies. If causal they also imply that smoking is responsible for many more deaths from leukaemia in adults than all other known causes combined.

\section{Introduction}

The veterans' smoking study, a prospective study of a cohort of United States veterans initiated in 1954, has been an important source of information on the effects of smoking on mortality. ${ }^{1-4}$ In the latest published analysis (1980), covering 16 years of observation (1954-69), a more than $50 \%$ increase in mortality from leukaemia was reported among current cigarette smokers as compared with non-smokers. ${ }^{+}$In this study we have investigated the relation between smoking and leukaemia with reference to the amount and type of tobacco smoked and also to certain subtypes of the disease.

\section{Subjects and methods}

Deaths from leukaemia in the period 1954-69 were identified among the 248046 United States veterans holding government life insurance policies who had provided details of their smoking habits in 1954 or 1957. Causes of death had been coded according to the seventh revision of the International Classification of Diseases (ICD). The computerised file details of cause of death, however, did not in all cases go beyond the first three digits of the ICD codes. In the seventh revision of the ICD leukaemia (code 204) is subdivided into certain subtypes by the fourth digit, as follows: 204.0, lymphatic leukaemia (chronic or unspecified); 204.1, myeloid leukaemia (chronic or unspecified) 204.2, monocytic leukaemia (any type); 204.3, acute leukaemia (of any type other than monocytic); 204.4 other and unspecified leukaemia. For our study those cases with only three digits computerised were coded more completely by reference to other records which showed the full four digit codes. Mortality from each of the above subtypes was then examined among non-smokers, current cigarette smokers, ex-cigarette smokers, and cigar and pipe smokers. The numbers of deaths recorded from a given type of leukaemia in current cigarette smokers were compared with the numbers expected if the rates recorded among the non-smokers had applied. These expected numbers were calculated by applying the age specific rates among the non-smokers to the man years at risk experienced by the smokers and the results summed across the age groups covered. Observed to expected ratios were also calculated according to the amount of tobacco smoked. A similar procedure was followed for ex-smokers of cigarettes as well as for cigar and pipe smokers. Evidence of dose-response relations was sought by using a standard test for trend for cohort studies.

Finally, because the ICD (7th revision) did not distinguish the different types of acute leukaemia an attempt was made to trace as many death certificates as possible of men in the study who had died of leukaemia.

\section{Results}

During the 16 years of observation 723 men in the study died of leukaemia, of whom 330 were current cigarette smokers, 185 ex-cigarette smokers, 46 cigar or pipe smokers, and 162 non-smokers, as recorded at entry to the study. There was a significant excess of leukaemia among current cigarette smokers as compared with non-smokers (relative risk 1.53, $\mathrm{p}<0.001$ (two sided test); table I). Of the specific types examined, significant excesses were found for myeloid and monocytic leukaemias and also for lymphatic leukaemia ( $p<0.001$ (two sided) in both cases).

When the relative risk of leukaemia was examined in relation to the number of cigarettes smoked a significant dose-response effect w.s found (table II). 